same six months in 2007 to 2014. The total number of cases identified in 2015 were 151.

Results

\begin{tabular}{|c|c|c|c|c|c|c|c|c|}
\hline & 2007 & 2008 & 2009 & 2011 & 2012 & 2013 & 2014 & 2015 \\
\hline \multicolumn{9}{|l|}{ (Had TOC\%) } \\
\hline C4 & 100 & 100 & 100 & 98.60 & 100 & 100 & 100 & 99.3 \\
\hline \multicolumn{9}{|c|}{ Treatment (\%) } \\
\hline PN (\%) & 82 & 95 & 92 & 98.60 & 100 & 100 & 100 & 96.7 \\
\hline PIL (\%) & 32 & 64 & 81 & 61 & 50 & 66 & 27 & 74 \\
\hline 1st line (\%) & 77 & 96 & 100 & 97 & 88 & 100 & 97 & 93.4 \\
\hline
\end{tabular}

Discussion/conclusion To my knowledge, this is the longest continuous audit of the management of N.gonorrhoea in the UK. I have seen continuous improvements in the performance of all five domains. We introduced an electronic reminder to provide patients with an information leaflet at the end of 2014. This has shown a marked improved from $27 \%$ to $74 \%$. We aim to achieve full BASHH compliance in 2016.

\section{P056 INFLUENCE OF COUNTRY OF BIRTH ON RISK OF STI DIAGNOSIS AMONG BLACK CARIBBEANS IN ENGLAND IN 2014}

Ana Harb*, Hamish Mohammed, Martina Furegato, Gwenda Hughes. Public Health England, London, UK

\subsection{6/sextrans-2016-052718.110}

Background/introduction In England, people of Black Caribbean (BC) ethnicity are disproportionately affected by sexually transmitted infections (STIs), but it is unclear whether this is associated with their country of birth.

Aim(s)/objectives To examine differences in STI diagnoses among UK- and Caribbean-born BC people.

Methods Data on STI diagnoses in BC people attending genitourinary medicine (GUM) clinics and living in England were obtained from the GUM Clinic Activity Dataset (GUMCADv2). Associations between being UK- or Caribbean-born and diagnosis with an STI were derived using univariate and multivariable multilevel logistic regression models adjusted for age, gender/sexualorientation, residence, and HIV status.

Results BC people made 231,719 attendances in 2014; $81.9 \%$ were UK-born. The median age (years) was 25 for UK-born and 34 for Caribbean-born people ( $\mathrm{p} \leq 0.001)$. Chlamydia, non-specific genital infection and gonorrhoea were the most commonly diagnosed STIs among UK- $(37.4 \%, 19.5 \%$ and $13.7 \%)$ and Caribbean-born attendees $(32.1 \%, 25.2 \%$ and 13.1\%). From the multilevel analysis, UK-born attendees were less likely to be diagnosed with chlamydia (aOR 0.87 [95\%C.I. 0.81-0.94]) and trichomoniasis (0.83 [0.71-0.97]), and more likely to be diagnosed with genital warts (1.24 [1.07-1.45]) than Caribbean-born attendees. The adjusted odds of a gonorrhoea diagnosis did not vary by country of birth.

Discussion/conclusion STI rates among black Caribbeans attending GUM clinics in England are high and might be influenced by STI epidemiology in their country of birth. Studies on the effectiveness of interventions aimed at reducing the burden of STIs in all black Caribbeans are urgently needed.

\section{P057 NEISSERIA GONORRHOEA (GC): PERSISTENCE OF DNA DETECTION AFTER SUCCESSFUL THERAPY AND CHANGING PATTERN OF ANTIBIOTIC SENSITIVITY, 2007-2015}

Sris Allan. Coventry \& Warwickshire Partnership NHS Ttrust, Coventry, UK

\subsection{6/sextrans-2016-052718.111}

Background/introduction Nucleic acid amplification testing (NAAT) is widely used in GUM clinics to diagnose GC infection; its in-built high sensitivity may potentially detect DNA from non-viable organisms following successful treatment. The BASHH national guidelines stipulate that test-of-cure (TOC) with NAAT should take place 2 weeks post-treatment. The purpose of this study was to determine whether this is an adequate time interval to perform TOC. We also analysed the changing pattern of antibiotic sensitivity between 2007-2015.

Aim(s)/objectives All GC cases at our clinic between 1st January and 30th June in 2007-2015 were identified and assessed for antibiotic sensitivity and TOC.

Methods In 2015 there were 151 cases; culture and sensitivity results were available for 99 cases. TOC with NAAT was done in 81 cases. There were 10 cases where the NAAT was SDA positive but PCR negative. Overall a TOC with NAAT was performed between 7 and 50 days post-treatment with a mean, median and mode of 17,14 and 14 days respectively.

\begin{tabular}{llllllllll} 
Abstract P057 Table 1 & \multicolumn{7}{c}{ Gonorrhoea } & $2007-2015$ \\
\hline & 2007 & 2009 & 2011 & 2012 & 2013 & 2014 & 2015 \\
\hline \% fully sensitive & 46 & 67 & 59 & 49 & 79 & 59 & 43 \\
Resistance to 1 antibiotic group & 27 & 15 & 20 & 38 & 10 & 20 & 23 \\
Resistance to 2 antibiotic groups & 15 & 10 & 16 & 8 & 6 & 13 & 21 \\
Resistance to 3 antibiotic groups & 12 & 2 & 5 & 3 & 2 & 8 & 5 \\
\hline
\end{tabular}

Conclusion None of the cultures were resistant to ceftriaxone. However prevalence of multi-drug resistance in N.gonorrhoea has shown gradual decline from $27 \%$ in 2007 to $8 \%$ in 2013. The trend has reversed in 2014 with increasing multi-drug resistance to $26 \%$ in 2015 . Since 2013 I have also looked at the persistence of DNA detection following successful therapy and this supports the BASHH Guidelines of TOC 2 weeks post treatment.

\section{P058 TWO CASES OF DELIBERATE ANTIRETROVIRAL OVERDOSE: RALTEGRAVIR AND TENOFOVIR DISAPROXIL FUMARATE/EMTRICITABINE}

Emma Wainwright*, Alan Tang, Fabian Chen. Royal Berkshire Hospltal NHS Foundation Trust, Reading, UK

10.1136/sextrans-2016-052718.112

Background/introduction There is a high incidence of psychiatric illness amongst those living with HIV. This is associated with a risk of deliberate self harm including overdose with antiretrovirals. There are a small number of publications describing overdose with antiretrovirals but none describing overdose with raltegravir.

Aim(s)/objectives In this report we aim to describe two cases of overdose with antiretrovirals: the management, investigations and resultant complications.

Methods The patient case notes and laboratory test results were reviewed. 